\title{
Chemical Effectors Cause Different Motile Behavior and Deposition of Bacteria in Porous Media
}

\author{
Celia Jimenez-Sanchez, ${ }^{\dagger}$ Lukas Y. Wick, ${ }^{\dagger}$ and José-Julio Ortega-Calvo ${ }^{* \dagger}$ \\ ${ }^{\dagger}$ Instituto de Recursos Naturales y Agrobiología de Sevilla (IRNAS-CSIC), Apartado 1052, E-41080-Seville, Spain \\ ${ }^{\ddagger}$ Helmholtz Centre for Environmental Research - UFZ, Permosertraße 15, D-04318 Leipzig, Germany.
}

\section{Supporting Information}

ABSTRACT: We tested the hypothesis whether chemically induced motility patterns of bacteria may affect their transport in porous media. Naphthalene-degrading Pseudomonas putida G7 cells were exposed to glucose, salicylate, and silver nanoparticles (AgNPs) and their motility was assessed by computer-assisted, quantitative swimming and capillary-based taxis determinations. Exposure to salicylate induced smooth movement with few acceleration events and positive taxis, whereas cells exposed to AgNPs exhibited tortuous movement and a repellent response. Although metabolized by strain G7, glucose did not cause attraction and induced a hyper-motile mode of swimming, characterized by a high frequency of acceleration events, high swimming speed $\left(>60 \mu \mathrm{m} \mathrm{s}^{-1}\right)$, and a high tortuosity in the trajectories. Chemically induced motility behavior correlated with distinct modes of attachment to sand in batch assays and breakthrough curves in percolation column experiments. Salicylate significantly reduced deposition of G7 cells in column experiments whereas glucose and AgNPs enhanced attachment and caused filter blocking that resulted in

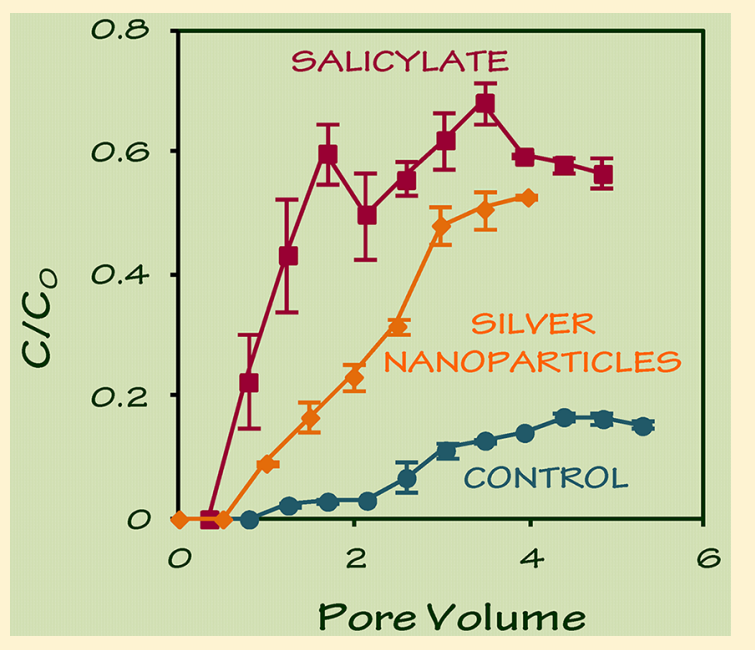
a progressive decrease in deposition. These findings are relevant for bioremediation scenarios that require an optimized outreach of introduced inoculants and in other environmental technologies, such as water disinfection and microbially enhanced oil recovery.

\section{INTRODUCTION}

The factors that influence the transport of microorganisms in the soil, sediment, and groundwater have gained attention because sufficient dispersal of active microorganisms is often not achieved during bioremediation. This limitation influences the delivery of pollutant-degrading microorganisms into the pollution source, such as during the bioremediation of groundwater. ${ }^{1}$ Bioremediation of soils and sediments may also be negatively affected, if the heterogeneous distribution of the pollutants and restricted phase exchanges result in a low pollutant bioavailability. ${ }^{2}$

Flagellar motility is the best known bacterial translocation mechanism. The swimming behavior allows bacterial cells to adapt to a wide range of environmental signals, such as spatial and temporal changes in light, temperature, and concentration of specific solutes (e.g., oxygen and organic chemicals). Motile bacteria can also be attracted to or repelled from environmental pollutants. ${ }^{3-6}$ Cells modify their swimming speed and/or mode because of these stimuli due to changes in flagellar rotation and redirect themselves to optimal places for physiological activity. ${ }^{7,8}$ The mobilizing potential of bacterial taxis has been demonstrated in laboratory-scale microcosms by enhanced biodegradation rates of naphthalene $\mathrm{g}^{9}$ and carbon tetrachloride ${ }^{10}$ due to chemotaxis.
Current knowledge indicates that motility may not always facilitate bacterial dispersal in porous environments, such as in soils or aquifers. The role of motility in enhancing bacterial adhesion to a variety of solid surfaces is a well-known phenomenon, ${ }^{11-14}$ and predicts that motile bacteria are poorly dispersed in porous media. Studies reporting precise measurements of transport of motile bacteria through porous systems are scarce; however, Camper et al. $^{15}$ showed that motile Pseudomonas fluorescens cells were detected at significantly lower numbers than immotile mutant cells in the effluents of breakthrough experiments with glass-packed columns. Other studies compared a motile groundwater Pseudomonas sp. strain and an immotile mutant, which showed an enhanced transport of immotile cells in laboratory experiments with glass-packed columns ${ }^{16}$ and in field experiments through fractured crystalline bedrock. ${ }^{17}$ The only available study on the effect of different swimming behaviors on transport through porous materials compared a wild-type Escherichia coli strain with full run-andtumble ability to immotile and smooth-swimming mutants of $E$.

Received: February 16, 2012

Revised: May 29, 2012

Accepted: May 29, 2012

Published: May 29, 2012 
coli and motile wild-type Pseudomonas putida, all showing different idling (or immotility) times when approaching solid surfaces. ${ }^{18}$ The study showed that different degrees of retardation and dispersion during transport through sand columns could be explained by dissimilar idling times. Greater understanding is needed regarding the role of single-cell motility in bacterial transport in porous systems with pollutantdegrading bacterial species relevant to bioremediation approaches.

We considered that we could modify cell deposition in porous media by applying substances that induce different motile behaviors in motile pollutant-degrading bacteria and experimentally examined this hypothesis by inducing hypermotility, attraction, and repulsion in the naphthalene-degrading strain P. putida G7. Cell motility upon exposure to glucose, salicylate, and silver nanoparticles (AgNPs) was characterized through computer-assisted motion analysis and capillary assays. ${ }^{4-6}$ A column percolation system was used as previously described $^{5,19,20}$ to assess the transport of exposed bacterial cells through sand under continuous flow conditions.

\section{MATERIALS AND METHODS}

Chemicals. Salicylate and glucose were obtained from Panreac Química SA (Barcelona, Spain). Silver nanopowder (maximum diameter $\leq 100 \mathrm{~nm}, 99 \%$ purity) and silver nitrate (>99\%) were purchased from Sigma-Aldrich, Inc. (St. Louis, MO, USA).

Bacteria, Media, and Cell Culture. The naphthalenedegrading strain Pseudomonas putida G7 was used in this study. This strain is motile due to polar flagella and is known to exhibit positive taxis toward naphthalene and salicylate ${ }^{5}$ and negative taxis toward AgNPs. ${ }^{6}$ The bacterium was grown and maintained as described elsewhere. ${ }^{5}$ Unless otherwise stated, all experiments were performed with bacteria grown at $30^{\circ} \mathrm{C}$ on a rotary shaker at $150 \mathrm{rpm}$ in Erlenmeyer flasks $(250 \mathrm{~mL})$ containing $100 \mathrm{~mL}$ of an inorganic salt solution $(\mathrm{MM})^{5}$ supplemented with $5 \mathrm{mM}$ salicylate. Cells were harvested after $48 \mathrm{~h}$ (early stationary phase, optical density or $\mathrm{OD}_{600}$ of 0.5 or $5 \times 10^{8}$ cells $\left.\mathrm{mL}^{-1}\right)$, which is the stage of the growth curve where this strain exhibited the highest proportion of motile cells. The cells were separated from the culture medium by centrifugation at $1000 \mathrm{~g}$ for $10 \mathrm{~min}$ and suspended in either MM or $\mathrm{MM}$ supplemented with the desired concentration of salicylate, glucose, or AgNPs. To avoid aggregation of AgNPs, ${ }^{6}$ the AgNP-containing stock solutions $\left(100 \mathrm{mg} \mathrm{L}^{-1}\right)$ were sonicated immediately before the experiments for $1 \mathrm{~h}$ at room temperature and diluted with $\mathrm{MM}$ or bacterial suspensions to result in a final concentration of $0.2 \mathrm{mg} \mathrm{L}^{-1}$ AgNPs.

Swimming Behavior. The swimming behavior of individual cells was determined in cell suspensions prepared as described above $\left(\mathrm{OD}_{600}=0.3\right.$ or $10^{8}$ cells $\left.\mathrm{mL}^{-1}\right)$ with a phase contrast Axioskop 2 Carl Zeiss light microscope (Jena, Germany). The microscope was connected to a Sony Exwave HD video camera (Tokyo, Japan). Computer-assisted motion analysis of the digitized images was performed with CellTrak as previously described (version 1.5, Motion Analysis Corporation, Santa Rosa, CA, USA). ${ }^{6}$ Briefly, 5-s videos were collected and analyzed for linear speed $(\mu \mathrm{m} / \mathrm{s})$ and rate of change of direction or RCDI (deg/s). These two mobility parameters were calculated over the entire length of individual paths. To guarantee the representativeness of the paths analyzed, the longest paths in each video were selected for analysis, eliminating cells with an average speed of less than 17 $\mu \mathrm{m} / \mathrm{s}$. Cells were defined as undergoing an acceleration event when their linear speed changed to a maximum value greater than $60 \mu \mathrm{m} \mathrm{s}^{-1}$. Turning events were computed when RCDI values achieved a peak with a maximum value greater than 1000

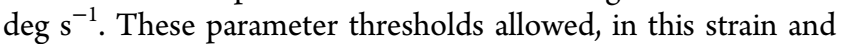
under our experimental conditions, the highest discrimination capacity among different motility patterns. ${ }^{6}$ To obtain a quantitative characterization of the motility behavior for the population of cells, the total numbers of acceleration and turning events were determined from duplicate experiments in 10 representative paths. The analysis of swimming behavior was performed immediately (i.e., within $1 \mathrm{~min}$ ) after preparation of the bacterial suspensions. We confirmed the stability of each behavior by motility analysis of suspensions that were maintained in the presence of the chemical effectors at least during $30 \mathrm{~min}$ (data not shown).

Our approach consisted of comparing the motility of suspensions exposed to chemical effectors, having unexposed suspensions as a control, that were prepared exactly in the same way as exposed suspensions. This allows reproducible results and excludes any additional influences on motility by centrifugation and by any metabolites, residual carbon sources, and any other chemicals (including molecular signals) present in batch cultures at early stationary phase of growth. For these reasons, and also because of the short exposure time periods and the higher optical density of the cultures at those stages (which causes difficulties for qualitative and quantitative analysis of motility) we did not attempt a detailed study of the motility in the cultures.

Optical microscopy was also used to confirm the loss of cell motility in the sonicated bacterial suspensions used in the transport experiments. The sonication procedure $(2 \mathrm{~h}$, Bransonic ultrasonic cleaner, $50-60 \mathrm{~Hz}$ ) was performed on ice to ensure that suspensions remained at room temperature (approximately $25{ }^{\circ} \mathrm{C}$ ) during the treatment. Under these conditions, more than $95 \%$ of the cells were immotile due to the breakage of bacterial flagella. The absence of motility in these suspensions was confirmed by optical microscopy during the transport experiments. No statistically significant differences in viability, quantified by determining the colony-forming units (cfu) that developed on tryptic soy agar (TSA), were observed after sonication ( $t$-test, $P=0.01)$. In contrast, a complete reduction $(>99 \%)$ in viability was observed upon exposure to $\mathrm{HgCl}_{2}\left(1.32 \mathrm{~g} \mathrm{~L}^{-1}\right)$ and complete loss of cell motility was confirmed by optical microscopy.

Tactic Response. The chemical-in-capillary $(\mathrm{CC})^{5}$ and chemical-in-pond $(\mathrm{CP})^{6}$ methods were used to characterize the tactic response of $P$. putida G7 cells to glucose, salicylate, and AgNPs. The techniques followed the same principle and were based on the quantification of viable cells that entered into a capillary as a result of taxis. The CC method is more sensitive for positive taxis, whereas the CP method is better applied to characterize repulsion. ${ }^{6}$ The chemical was located in the capillary or in the bacterial suspension for the CC and CP assays, respectively. The concentrations of chemicals and bacteria were adapted to each method to increase sensitivity. ${ }^{5,6}$ The CC assays were performed with $100 \mathrm{mM}$ glucose, $100 \mathrm{mM}$ sodium salicylate, or $0.2 \mathrm{mg} \mathrm{L}^{-1} \mathrm{AgNPs}$ and had a cell suspension with an optical density $\left(\mathrm{OD}_{600}\right)$ of $0.02\left(10^{6}\right.$ cell $\left.\mathrm{mL}^{-1}\right)$. The CP method used solutions of glucose $(10 \mathrm{mM})$ and AgNPs $\left(0.2 \mathrm{mg} \mathrm{L}^{-1}\right)$ and a cell density (measured as $\left.\mathrm{OD}_{600}\right)$ of $0.6\left(10^{9}\right.$ cell $\left.\mathrm{mL}^{-1}\right)$. To perform the assays, $0.2 \mathrm{~mL}$ 

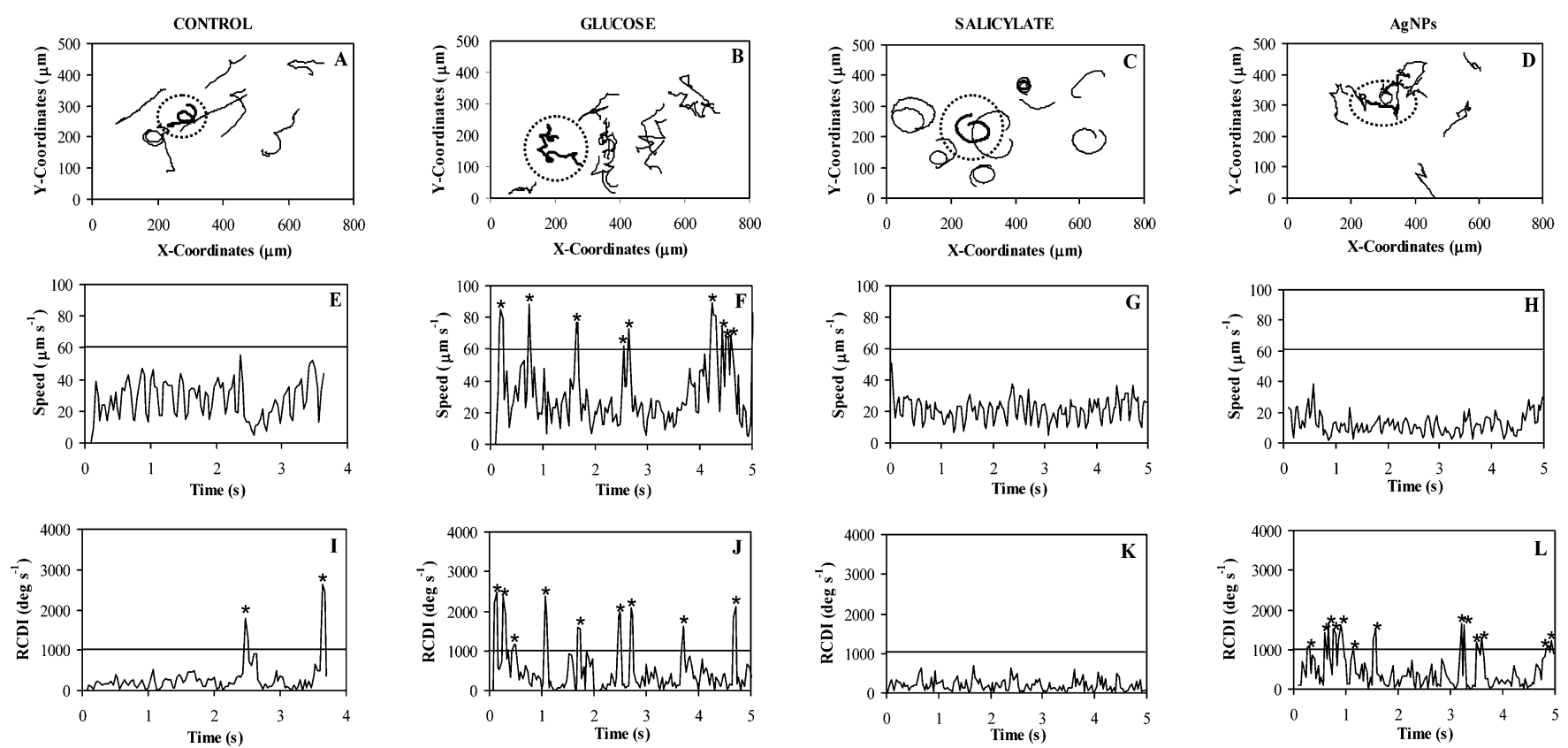

Figure 1. Analysis of the swimming behavior of Pseudomonas putida G7 in the presence of glucose (10 mM; B, F, and J), salicylate (10 mM; C, G, and $\mathrm{K}$ ), silver nanoparticles (AgNPs, $0.2 \mathrm{mg} \mathrm{L}^{-1} ; \mathrm{D}, \mathrm{H}$, and L), and control (A, E, and I). Ten representative motility paths are shown in (A), (B), (C), and (D) and represent the shape of the trajectories. The time-course of speed $(\mathrm{E}-\mathrm{H})$ and the rate of change of direction or RCDI (I-L) correspond to the individual paths indicated as thicker lines surrounded by dotted rings in (A-D). Horizontal lines represent the threshold values for acceleration $(\mathrm{E}-\mathrm{H})$ or turning $(\mathrm{I}-\mathrm{L})$ events. The events are indicated by asterisks.

of the bacterial suspension was placed in a small chamber formed by placing two capillary tubes $(1 \mu \mathrm{L})$ (Microcaps; Drummond, Broomall, PA, USA) in parallel on a microscope slide that was covered by a glass coverslip. Another capillary tube $(1 \mu \mathrm{L})$ that contained the appropriate solution and was heat-sealed at one end was immersed in the cell suspension at its open end. The chambers were incubated for $30 \mathrm{~min}$. The number of bacterial cells accumulated in the test capillaries was quantified by determining the cfu that developed on TSA., Each assay was performed with three capillaries per chamber. A control with no chemical effector in the chamber was also included in each experiment. Statistical comparisons of treatments within each assay were performed using analysis of variance and Scheffé posthoc tests at $P=0.05$.

Cell Surface Properties. Cell surface hydrophobicity was derived from the static contact angles $\left(\theta_{\mathrm{w}}\right)$ of small water droplets placed on filters covered with layers of bacteria. Measurements were performed with a goniometer microscope (Krüss GmbH, Hamburg, Germany) as previously described. ${ }^{5}$ Contact angles of at least 10 droplets of $1 \mu \mathrm{L}$ were measured for each treatment. The zeta potential $(\zeta)$ was approximated from the electrophoretic mobility, which was measured by a Doppler electrophoretic light-scattering analyzer (Zetamaster; Malvern Instruments, Malvern, UK) according to the method of Helmholtz-Smoluchowski. ${ }^{5}$

Adhesion and Column Deposition Experiments. Sand. Fine-grained sand was obtained from Panreac Quimica SA (Barcelona, Spain) and washed by gravity settling in deionized water. A fraction of $250-400-\mu \mathrm{m}$ grain size was obtained by sieving.

Adhesion. Batch adhesion experiments were performed in duplicate with sand to test the bacterial affinity to the sand while exhibiting different motility behaviors in a nonflowing system. The bacterial suspension was prepared using solutions of different effectors (glucose and salicylate at $10 \mathrm{mM}$, and
AgNPs, prepared as described above, at a concentration of 0.2 $\mathrm{mg} \mathrm{L}{ }^{-1}$ ) to give $\mathrm{OD}_{280}$ of 1.7 (corresponding to $\mathrm{OD}_{600}=0.3$ or $10^{8}$ cells $\left.\mathrm{mL}^{-1}\right)$. Sand $(1.5 \mathrm{~g}$ ) was introduced into a $20-\mathrm{mL}$ glass vial and gently mixed by shaking with $1 \mathrm{~mL}$ of the bacterial suspension for $30 \mathrm{~min}$ at $80 \mathrm{rpm}$. The sand particles were then separated by decanting for $1 \mathrm{~min}$, and the percentage of adhered cells was estimated from the loss of the initial $\mathrm{OD}_{280}$ in the supernatant.

Column Experiments. Transport experiments were performed in duplicate at $25{ }^{\circ} \mathrm{C}$ in vertical percolated columns. ${ }^{5,19,20}$ The sand was wet-packed in glass columns that were $10 \mathrm{~cm}$ long and $0.9 \mathrm{~cm}$ internal diameter. The amount of dry packing material present in each column was approximately $12 \mathrm{~g}$. The columns were connected to a peristaltic pump, and suspensions of salicylate-grown bacteria, which were prepared as described above $\left(\mathrm{OD}_{600}=0.3\right)$, were pumped through the columns at a constant flow rate $(0.14 \mathrm{~mL}$ $\left.\min ^{-1}\right)$. The hydraulic flow rate was $0.37 \mathrm{~cm} \mathrm{~min}^{-1}$, and the porosity was 0.42 (estimated gravimetrically), which corresponded to a pore volume (PV) of $2.67 \mathrm{~mL}$. Glucose and salicylate were introduced into the column influents along with the bacterial cells at a concentration of $10 \mathrm{mM}$, whereas AgNPs were prepared as described above and introduced at a concentration of $0.2 \mathrm{mg} \mathrm{L}^{-1}$. These influent concentrations were chosen, in accordance with motility analysis and previous work, ${ }^{5}$ to ensure a distinct motility behavior during the passage of the cells through the columns. Column breakthrough of bacteria was followed photometrically at various time intervals. The efficiency of bacterial removal was expressed as the $\mathrm{OD}_{600}$ in column effluent $(C)$ divided by the $\mathrm{OD}_{600}$ in the column influent $\left(C_{0}\right)$. All results are provided as the mean measurement from duplicate experiments. Other experimental details and controls performed to exclude bacterial proliferation during the experiments are described elsewhere. ${ }^{5,19,20}$ 
Table 1. Influence of Motile Behavior of Pseudomonas putida G7 Cells on Adhesion to Sand and Deposition during Transport in Saturated Sand Columns

\begin{tabular}{|c|c|c|c|c|c|c|c|c|c|}
\hline \multirow[b]{2}{*}{ motility } & \multirow[b]{2}{*}{ treatment } & \multicolumn{2}{|c|}{ motility analysis $^{a}$} & \multicolumn{2}{|c|}{ cell surface ${ }^{a}$} & \multirow[b]{2}{*}{ adhesion $^{a, b}(\%)$} & \multicolumn{3}{|c|}{ deposition $^{c, d}$} \\
\hline & & acceleration events $^{e}$ & turning events ${ }^{f}$ & $\theta_{\mathrm{w}}^{g}\left({ }^{\circ}\right)$ & $\zeta^{h}(\mathrm{mV})$ & & $\alpha_{\mathrm{t}}^{i}$ & $\mathrm{C} / \mathrm{C}_{0}{ }^{j}$ & $\mathrm{PV}^{k}$ \\
\hline intrinsic & control & $18 \pm 0.3$ & $51 \pm 0.7$ & $47 \pm 6$ & $-31 \pm 2$ & $37.9 \pm 1.7$ & $0.93(0.72)$ & $0.04(0.08)$ & $1.61(4.86)$ \\
\hline immotile & sonication & 0 & 0 & $69 \pm 9$ & $-34 \pm 3$ & $8.18 \pm 1.8$ & $0.28(0.18)$ & $0.37(0.53)$ & $1.61(4.86)$ \\
\hline killed cells & $\mathrm{HgCl}_{2}$ & 0 & 0 & $48 \pm 7$ & $-31 \pm 2$ & $9.28 \pm 4.6$ & $0.13(0.04)$ & $0.55(0.83)$ & $1.55(3.62)$ \\
\hline hyper-motility & glucose & $76 \pm 3$ & $78 \pm 18$ & $47 \pm 4$ & $-29 \pm 2$ & $54.9 \pm 2.1$ & $1.18(0.24)$ & $0.02(0.44)$ & $1.18(4.65)$ \\
\hline positive taxis & salicylate & $20 \pm 4$ & 0 & $36 \pm 2$ & $-36 \pm 2$ & $7.80 \pm 1.1$ & $0.13(0.14)$ & $0.57(0.60)$ & $1.68(4.82)$ \\
\hline negative taxis & AgNPs & $9 \pm 3$ & $114 \pm 3$ & $48 \pm 5$ & $-32 \pm 2$ & $57.6 \pm 4.4$ & $0.69(0.18)$ & $0.09(0.53)$ & $1.00(3.97)$ \\
\hline
\end{tabular}

${ }^{a}$ Values are reported as mean \pm one standard deviation. ${ }^{b}$ Percentage of cells adhered to sand. ${ }^{c}$ Experimental errors are not included here for clarity (see Figure 3). ${ }^{d}$ Final experimental values are given in parentheses as an indication of the dynamics of filter blocking. ${ }^{e}$ Total number of runs with a maximum speed greater than $60 \mu \mathrm{m} \mathrm{s}^{-1}$. ${ }^{f}$ Total number of turning events (rate of change of direction greater than 1000 deg s${ }^{-1}$ ). ${ }^{g} \theta_{\mathrm{w}}$, contact angle. ${ }_{h} \zeta$, zeta potential. ${ }^{i} \alpha_{\mathrm{t}}$ adhesion efficiency ${ }^{j} \mathrm{C} / \mathrm{C}_{0}$, transport efficiency. ${ }^{k} \mathrm{PV}$, pore volume.

Calculations. The adhesion efficiency $\left(\alpha_{\mathrm{t}}\right)$ of bacteria is commonly defined as the ratio of the rate of attachment $\left(\eta_{\mathrm{t}}\right)$ to the rate of bacterial transport to the surface $\left(\eta_{\text {trans }}\right)$

$$
\alpha_{\mathrm{t}}=\eta_{\mathrm{t}} / \eta_{\text {trans }}
$$

In the absence of repulsive forces, $\alpha_{\mathrm{t}}$ approaches unity; however, it falls below unity in the presence of repulsive forces. Unlike $C / C_{0}$, which is an overall measurement for cell removal, the calculation of $\alpha_{\mathrm{t}}$ accounts for differential frequencies of contact with the column material for the bacteria. Values of $\eta_{\text {trans }}$ were calculated by accounting for the contributions of convection, diffusion, van der Waals attraction, and sedimentation. For the calculations, we assumed that the packing was composed of spheres of identical size (a radius of $250-400 \mu \mathrm{m}$ for the sand grains) in their closest packing and identical effective bacterial radii $(R)$. Values of $\eta_{\mathrm{t}}$ were calculated from $C / C_{0}$ values obtained in the transport experiments. ${ }^{5}$

\section{RESULTS}

Motile Behavior. Swimming. Experiments were designed to test the effects of glucose, salicylate, and AgNPs on single cell motility. The strain showed an intrinsic mode of swimming characterized by short trajectories and abrupt changes of direction in control experiments with no test substance added (Figure 1A, E, and I). When exposed to glucose, which can be used by this strain as a source of carbon and energy, the cells exhibited a hyper-motility mode of swimming that was characterized by acceleration events with maximum speeds often exceeding $60 \mu \mathrm{m} \mathrm{s}^{-1}$ and a higher tortuosity in their trajectories due to an increase in the number of turning events (Figure 1B, F, and J). Exposure to a positive (salicylate) ${ }^{5}$ and negative $(\mathrm{AgNPs})^{6}$ tactic effector also induced distinct swimming behaviors. With salicylate, acceleration events were rarely observed and changes of direction of individual cells were less frequent, which resulted in smooth movement (Figure 1C, $\mathrm{G}$, and $\mathrm{K}$ ). RCDI values remained below $1000 \mathrm{deg} / \mathrm{s}$, which reflected the absence of turning events (Figure $1 \mathrm{~K}$ ). In the presence of AgNPs, the changes of direction were much more frequent and abrupt (Figure 1D, H and L), which resembled the hyper-motility mode of swimming observed in the presence of glucose. However, the maximum observed speed in AgNPexposed cells was rarely greater than $60 \mu \mathrm{m} \mathrm{s}^{-1}$ (Figure $1 \mathrm{H}$ ). To obtain an estimate of the population, 10 representative paths were analyzed in duplicate experiments for each motile behavior (Table 1). The quantification of the number of acceleration and turning events provided a distinct profile.
Hyper-motility and repellent responses yielded more turning events than the control. However, hyper-motility was characterized by a 7-fold higher number of acceleration events. The apparent positive taxis behavior corresponded to a complete absence of turning events. Due to the inherent variability of movement among individual cells, no statistically significant differences were observed between the average values of linear speed and RCDI for each motile behavior (data not shown). The video files used for these calculations can be downloaded from the following: http://hdl.handle.net/10261/ 45677.

Tactic Response. Exposure to glucose, salicylate, and AgNPs resulted in a distinct tactic response in Pseudomonas putida G7, which was determined in the $\mathrm{CC}$ and $\mathrm{CP}$ assays. In the CC experiments, cells were attracted by salicylate but not by AgNPs or glucose (Figure 2A). In the $\mathrm{CP}$ experiments (Figure 2B), cells exposed to glucose accumulated in the glucose-free capillaries at statistically higher numbers than in the controls without glucose, and to the same extent, in controls containing glucose in the capillary and pond. This result may be explained by the hyper-motility observed in the presence of glucose (Figure 1). It is also possible that hyper-motility caused in CC experiments (Figure 2A) a higher tendency of cells entering the glucose-containing capillaries to exit from the capillaries due to an increased dispersion, thus causing lower cfu counts than in the controls. Cell proliferation could be considered negligible during the experiments, which was shown by a doubling time of $15 \mathrm{~h}\left(\mu=0.05 \mathrm{~h}^{-1}\right)$ for growth on glucose (theoretically, only $10^{5}$ cells $\mathrm{mL}^{-1}$ would have been produced during the $30 \mathrm{~min}$ of experimentation, which would have contributed $0.01 \%$ of the initial cell concentration). When suspended in a salicylatecontaining medium, cells accumulated due to chemotaxis at significantly lower numbers in the salicylate-free capillaries when compared with the control (Figure 2B). The diminished CFU counts in control chambers containing salicylate in both sides (pond and capillaries) can be explained by a lower dispersion tendency of motile bacteria when immediate growth substrate resources are abundant. ${ }^{21} \mathrm{We}$ concluded that the bacterium reacted differently to glucose and salicylate possibly as a result of acclimation to salicylate during precultivation. Strain G7 cells exposed to AgNPs exhibited a statistically significant $(P \leq 0.01) 3$-fold accumulation in the AgNP-free capillaries, and the accumulation did not occur when the chemical was placed in both sides of the chamber (Figure $2 \mathrm{~B}$ ). This profile in CP experiments is evidence for negative taxis, and extends previous observations of tactic response to AgNPs in this strain growing exponentially in tryptic soy broth. ${ }^{6}$ 

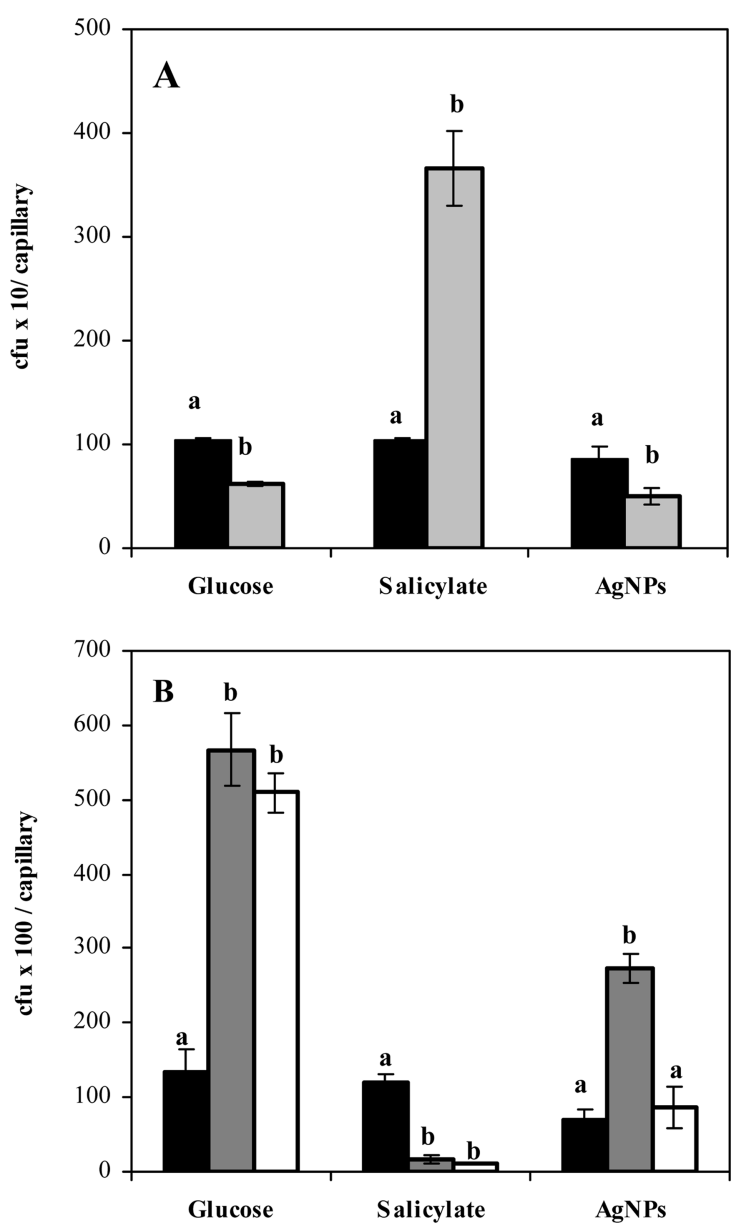

Figure 2. Tactic response of Pseudomonas putida G7 to glucose, salicylate, and silver nanoparticles (AgNPs) determined by chemicalin-capillary (A) and chemical-in-pond (B) assays. In A, the gray and black bars indicate, respectively, the number of colony forming units (cfu) detected in capillaries with and without the chemicals. In B, gray bars indicate the number of cfu in the capillaries when the chemical was present in the pond only, as compared with the control without the chemical (black bar). White bars in B indicate the cfu in the capillaries with assays placing the chemicals in both sides of the chamber (pond and capillary) to control for a modified motility. As the chemicals were tested in separate experiments, and to account for the inherent variability of capillary assays, the data from controls without the chemicals (black bars in A and B) are separately reported for each experiment. The error bars denote the standard deviation of the mean $(n=3)$. In each experiment, values labeled with the same letter are not significantly different $(P \leq 0.05)$.

Cell Surface Properties, Adhesion, and Deposition. Cell Surface Properties. Water contact angles $\left(\theta_{\mathrm{W}}\right)$ and zeta potentials $(\zeta)$ were used to describe the physicochemical surface properties of $P$. putida G7. The strain was negatively charged and exhibited a zeta potential $(-31 \pm 2 \mathrm{mV})$ and water contact angle $\left(47 \pm 6^{\circ}\right)$ of intermediately hydrophobic cell surfaces. In general, no significant changes of the physicochemical cell surface properties were observed when strain G7 was treated to change its swimming properties (Table 1). After 90 min of exposure to the chemicals no significant differences in cell surface properties were observed, except for the contact angle value of sonicated cells $\left(69 \pm 9^{\circ}\right)$. This slight increase in hydrophobicity could be explained by an eventual modification of the cell surface composition after sonication, which would have exposed hydrophobic cell surface components after breaking the flagella and removing hydrophilic polymers surrounding the cells. An analogous effect on cell surface hydrophobicity has recently been described for P. putida cells exposed to a variety of toxins. ${ }^{22}$

For all experiments, we used early stationary cells with average dimensions of $1 \mu \mathrm{m}$ wide and $3 \mu \mathrm{m}$ long. ${ }^{5}$ No change in cell size or shape was observed by optical microscopy upon sonication or exposure to $\mathrm{HgCl}_{2}$, glucose, salicylate, or AgNPs.

Adhesion. In batch experiments, $P$. putida attached to sand at different rates depending on motility (Table 1). Under control conditions, approximately $40 \%$ of the cells attached to the sand. Adhesion significantly decreased to the same extent in sonicated cells, cells inactivated with $\mathrm{HgCl}_{2}$, and motile cells experiencing positive taxis $(P \leq 0.05)$. Hyper-motility and negative taxis significantly enhanced attachment when compared with cells exhibiting intrinsic motility $(P \leq 0.05)$.

Deposition. Control cells were transported through sand to a minor extent, and reached final $C / C_{0}$ values of approximately 0.1 (Figure 3). Suspensions of immotile (sonicated) cells
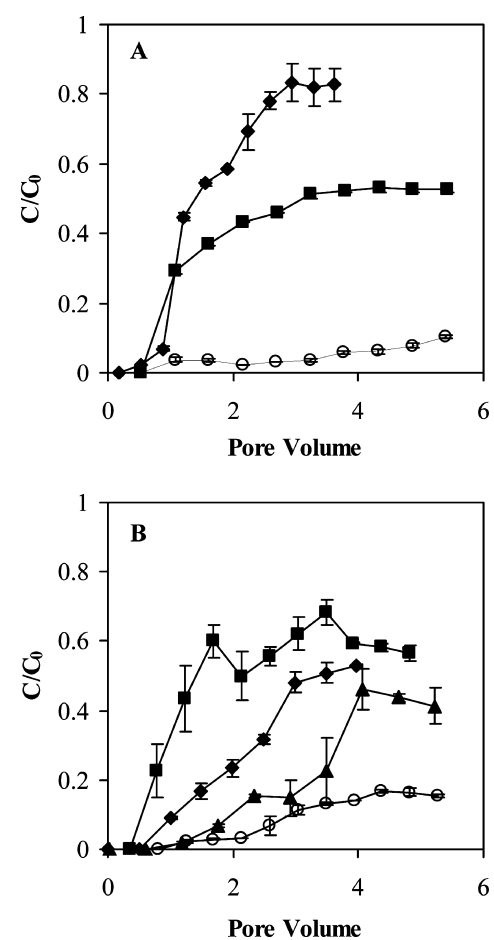

Figure 3. Breakthrough curves of Pseudomonas putida G7 transported through sand-filled columns. (A) Effect of sonication (squares) and inactivation with $\mathrm{HgCl}_{2}$ (diamonds). (B) Effect of exposure to glucose to induce hyper-motility (triangles), to salicylate (promoting positive taxis, squares) and to silver nanoparticles (repulsion, diamonds). Bacterial fronts were detected after 30-40 min from the start of experiments. Controls with no treatment (circles) are reported in each transport experiment. Error bars represent one standard deviation of duplicate columns.

pumped through sand-packed columns broke through up to a $C / C_{0}$ value of $\sim 0.4$ after 1.6 pore volumes and resulted in a final $C / C_{0}$ value of $\sim 0.5$, which indicated an approximate decrease of $40 \%$ in the deposition of this strain as a result of sonication (Figure 3A). A further increase in transport was observed with cells killed with $\mathrm{HgCl}_{2}$ (final $C / C_{0}=0.8$ ). We hypothesize that the efficiency of cell adhesion to sand surfaces under flowing conditions is directly related to the intrinsic motility of the cells because $\alpha_{\mathrm{t}}$ values were significantly lower 
with immotile and killed cells (Table 1). Slight differences between sonicated and killed bacterial cells could explain the lower $C / C_{0}$ values reached with sonicated bacterial suspensions. The absence of motility caused by these treatments may reveal the influence of other characteristics on transport. The higher hydrophobicity of sonicated cells (Table 1), as well as the hydrodynamic properties of killed cells possessing immotile flagella, may have contributed to these differences.

The role of motility on the transport of strain G7 through sand was also investigated using glucose to induce hypermotility during passage through the columns. The progressive increase of $C / C_{0}$ values after two pore volumes (Figure 3B) may be due to substratum blocking by attached cells. ${ }^{23}$ This result suggests that hyper-motile cells approaching the sand grains experienced a higher apparent affinity for sand surfaces than cells exhibiting intrinsic motility. The subsequent blocking caused by the attachment of hyper-motile cells is supported by the evolution of calculated $\alpha_{\mathrm{t}}$ values, which showed a significant decline (from 1.18 to 0.24 ) during the experiments (Table 1 ). This decline indicated that attached cells precluded further adhesion upon continuous percolation. Both positive and negative tactic behaviors also promoted bacterial transport through sand; however, the breakthrough curves were different (Figure 3B). In bacterial suspensions containing salicylate, a high $C / C_{0}$ value $(0.57)$ was reached at breakthrough, and the rate of cell retention was constant after that point. The values of $C / C_{0}$ were initially low (0.09) during transport of cells exposed to AgNPs, but the values progressively increased after one pore volume because of collector saturation and reached a final $C / C_{0}$ value of 0.5 (Table 1 ). The slight tailing of the biomass concentration in the effluent during subsequent flushing with AgNPs-free MM can be ascribed to reversible adhesion of a small fraction of the cells (Figure S1). Adhered cells were, however, recovered from the columns by flushing with distilled water, which was expected as an effect of a decreased ionic strength within the columns.

The stability of the motile behavior was confirmed in each transport experiment by optical microscopy observations and motility analysis of column influents and effluents. The analysis of the swimming mode of cells present in the effluent after percolation of 2 pore volumes of a bacterial suspension containing AgNPs (Figure 3B) yielded a total number of acceleration and turning events of $14 \pm 9$ and $89 \pm 3$, respectively. These figures are consistent with the negative taxis profile shown in Table 1 and confirmed the tactic detection of AgNPs in the column effluents.

\section{DISCUSSION}

Our data demonstrate that changes in single cell motility due to chemical effectors have direct effects on bacterial transport because (i) salicylate, glucose, and AgNPs induced changes in motility (hyper-motility and taxis) and cell adhesion in batch assays, (ii) the changes were associated with modified breakthrough curves and enhanced transport in column experiments, and (iii) these chemicals did not modify the cell surface properties of the bacteria.

The significant deposition of control cells in the sand columns when compared with the sonicated and killed cells can be attributed to increased cell attachment to the sand due to intrinsic motility. This observation is supported by the results from adhesion experiments under batch conditions, which showed a significant decline in cell adhesion upon suppression of motility. In fact, motility has frequently been identified as a bacterial trait that promotes in vitro cell attachment to a variety of surfaces, including glass, ${ }^{11,12}$ intestinal surfaces, ${ }^{13}$ and plant roots. ${ }^{14}$ The direct comparison of transport capacities of immotile and motile cells through flowing porous systems has been less explored; however, several studies have indicated that bacterial transport through glass- and sand-packed columns can also be negatively affected in motile cells and is attributed to the increased tendency for attachment to the substrate. ${ }^{15,16,18}$ Because our approach was based on directly relating motility observations to transport results, the exact physical mechanisms by which intrinsic motility enhances cell attachment remain unknown. However, based on previous research, ${ }^{16}$ we postulate that motile cells may exhibit an increase in the rate of approaching collector surfaces; therefore, the rate of attachment is increased when compared to immotile cells.

Our results also show that deposition of motile bacterial cells can be significantly modified. The different motility modes were induced in our experiments with cells at the early stationary phase of growth, which is when this strain showed the highest motility. With salicylate, cells exhibited a tactic attraction and smooth movement that is typical for chemotaxis in this strain. ${ }^{5}$ The observed hyper-motility of strain G7 in the presence of glucose but not salicylate is surprising and has not been previously described to our knowledge. Such distinct behavior is also reflected by the absence of apparent chemotactic responses of salicylate-grown cells to glucose despite their metabolic potential to grow on glucose. The hyper-motility of the cells may be interpreted as a potential stress response or energy overflow mechanism of the bacteria. We can conclude that the observed motility behaviors were not the result of growth on glucose or salicylate, but rather a fast reaction triggered by the exposure to these chemicals, and that these motility modes were maintained during at least the time period of capillary, adhesion, and transport experiments. Nevertheless, it is possible that, after more extended time periods than those considered in this study, exposure to these chemicals would cause in bacteria to adopt planktonic or sessile lifestyles, with differentiated modes of motility and adhesion, during their proliferation within the porous medium. In our study, cells also reacted promptly, in the absence of any source of carbon and energy, to low (but environmentally relevant) ${ }^{24}$ concentrations of AgNPs through negative taxis, possibly as a prelude for a toxicity effect. ${ }^{6}$

These different motility modes may have modified the mode of interaction with the solid surfaces. Indeed, the reduced deposition caused by the exposure to salicylate is likely the effect of a reduced probability of cell interception by collector surfaces due to smooth movements and the absence of turning events (Figure $1 \mathrm{~K}$ ). The proposed mechanism for transport enhancement agrees with the observations of batch adhesion experiments, which indicated less adhesion upon exposure to salicylate when compared with intrinsic motility. The proposed mechanism also agrees with a previous study that determined enhanced transport as a result of exposure to positive chemoeffectors (naphthalene and different organic acids, including salicylate) during the passage of cells of this strain through porous materials. ${ }^{5}$ Our results also show that negative taxis and hyper-motility may promote transport through a mechanism related to the saturation of collector surfaces. Our motility analysis and batch adhesion assays demonstrated that the higher number of turning events observed in hyper-motility and negative taxis were correlated with enhanced cell adhesion. The high tumbling frequency and saturation of the collector 
due to extensive attachment may explain in this way the progressively lower $\alpha_{\mathrm{t}}$ values and a net enhancement of transport. Alternately, the progressive breakthrough of cells in the packed sand column experiments could be caused by a reversible attachment to sand mediated by motility of chemotactic or hypermotile cells. However, the results from experiments of substitution of the cell suspension by MM (Figure S1) indicated that this explanation is unlikely.

Our study may have implications for the design of new bioremediation strategies oriented to a controlled dispersal of degrading bacteria. Treatment of extended areas of contamination and pollutants present at a certain depth can benefit from the use of positive chemical effectors that increase the outreach of introduced inoculants. In the specific case of salicylate, this positive aspect could be added to its biostimulant effect as an inducer of PAH metabolism. The benefits can also be extended to bioremediation scenarios involving nonaqueousphase liquids, which present additional complications due to restricted pollutant bioavailability. ${ }^{25,26}$ For localized and surface contamination of soils and aquifers, negative chemoeffectors and alternate carbon sources (causing hyper-motility) would help to rapidly confine motile bacteria at the contaminated site and would be specially useful for aged hydrophobic pollutants, such as polycyclic aromatic hydrocarbons, ${ }^{2 f}$ to promote the association of bacteria with the solid phase of the contaminated materials. Other applications of this work may be related to rhizosphere bioremediation, ${ }^{4}$ water disinfection that employs antimicrobial nanomaterials, ${ }^{28}$ and microbially enhanced oil recovery. ${ }^{29}$ These innovations should obviously consider extending this work to other chemical effectors and other environmental strains, which will be the subject of future research.

\section{ASSOCIATED CONTENT}

\section{(S Supporting Information}

Figure S1. This material is available free of charge via the Internet at http://pubs.acs.org.

\section{AUTHOR INFORMATION}

\section{Corresponding Author}

*Tel: (+34) 95-4624711; fax: (+34) 95-4624002; e-mail: jjortega@irnase.csic.es.

\section{Notes}

The authors declare no competing financial interest.

\section{ACKNOWLEDGMENTS}

Experimental help by Jana Reichenbach and Birgit Würz (UFZ) is greatly appreciated. Support for this research was provided by the Spanish Ministry of Science and Innovation (grants CGL2007-64199 and CGL2010-22068-C02-01) and the CSIC JAE Programme (C.J.-S.).

\section{REFERENCES}

(1) Scow, K. M.; Hicks, K. A. Natural attenuation and enhanced bioremediation of organic contaminants in groundwater. Curr. Opin. Biotechnol. 2005, 16, 246-253.

(2) Bosma, T. N. P.; Middeldorp, P. J. M.; Schraa, G.; Zehnder, A. J. B. Mass transfer limitation of biotransformation: Quantifying bioavailability. Environ. Sci. Technol. 1997, 31, 248-252.

(3) Pandey, G.; Jain, R. K. Bacterial chemotaxis toward environmental pollutants: Role in bioremediation. Appl. Environ. Microbiol. 2002, 68, 5789-5795.
(4) Ortega-Calvo, J. J.; Marchenko, A. I.; Vorobyov, A. V.; Borovick, R. V. Chemotaxis in polycyclic aromatic hydrocarbon-degrading bacteria isolated from coal-tar- and oil-polluted rhizospheres. FEMS Microbiol. Ecol. 2003, 44, 373-381.

(5) Velasco-Casal, P.; Wick, L. Y.; Ortega-Calvo, J. J. Chemoeffectors decrease the deposition of chemotactic bacteria during transport in porous media. Environ. Sci. Technol. 2008, 42, 1131-1137.

(6) Ortega-Calvo, J. J.; Molina, R.; Jimenez-Sanchez, C.; Dobson, P. J.; Thompson, I. P. Bacterial tactic response to silver nanoparticles. Environ. Microbiol. Rep. 2011, 3, 526-534.

(7) Amsler, C. D.; Cho, M. S.; Matsumura, P. Multiple factors underlying the maximum motility of Escherichia coli as cultures enter post-exponential growth. J. Bacteriol. 1993, 175, 6238-6244.

(8) Harwood, C. S.; Fosnaugh, K.; Dispensa, M. Flagellation of Pseudomonas putida and analysis of its motile behavior. J. Bacteriol. 1989, 171, 4063-4066.

(9) Marx, R. B.; Aitken, M. D. Bacterial chemotaxis enhances naphthalene degradation in a heterogeneous aqueous system. Environ. Sci. Technol. 2000, 34, 3379-3383.

(10) Witt, M. E.; Dybas, M. J.; Worden, R. M.; Criddle, C. S. Motility-enhanced bioremediation of carbon tetrachloride-contaminated aquifer sediments. Environ. Sci. Technol. 1999, 33, 2958-2964.

(11) Korber, D. R.; Lawrence, J. R; Sutton, B.; Caldwell, D. E. Effect of laminar flow velocity on the kinetics of surface recolonization by mot+ and mot- Pseudomonas fluorescens. Microb. Ecol. 1989, 18, 1-19.

(12) McClaine, J. W.; Ford, R. M. Reversal of flagellar rotation is important in initial attachment of Escherichia coli to glass in a dynamic system with high- and low-ionic-strength buffers. Appl. Environ. Microbiol. 2002, 68, 1280-1289.

(13) Attridge, S. R.; Rowley, D. The role of the flagellum in the adherence of Vibrio collerae. J. Infect. Dis. 1983, 147, 864-872.

(14) De Weger, L. A.; Van Der Vlugt, C. I. M.; Wijfjes, A. H. M.; Bakker, P.; Schippers, B.; Lugtenberg, B. Flagella of a plant-growthstimulating Pseudomonas fluorescens strain are required for colonization of potato roots. J. Bacteriol. 1987, 169, 2769-2773.

(15) Camper, A. K.; Hayes, J. T.; Sturman, P. J.; Jones, W. L.; Cunningham, A. B. Effects of motility and adsorption rate coefficient on transport of bacteria through saturated porous media. Appl. Environ. Microbiol. 1993, 59, 3455-2462.

(16) Becker, M. W.; Collins, S. A.; Metge, D. W.; Harvey, R. W.; Shapiro, A. M. Effect of cell physicochemical characteristics and motility on bacterial transport in groundwater. J. Contam. Hydrol. 2004, 69, 195-213.

(17) Becker, M. W.; Metge, D. W.; Collins, S. A.; Shapiro, A. M.; Harvey, R. W. Bacterial transport experiments in fractured crystalline bedrock. Ground Water 2003, 41, 682-689.

(18) Liu, J.; Ford, R. M.; Smith, J. A. Idling time of motile bacteria contributes to retardation and dispersion in sand porous medium. Environ. Sci. Technol. 2011, 45, 3945-3951.

(19) Ortega-Calvo, J. J.; Fesch, C.; Harms, H. Biodegradation of sorbed 2,4-dinitrotoluene in a clay-rich, aggregated porous medium. Environ. Sci. Technol. 1999, 33, 3737-3742.

(20) Lahlou, M.; Harms, H.; Springael, D.; Ortega-Calvo, J. J. Influence of soil components on the transport of polycyclic aromatic hydrocarbon-degrading bacteria through saturated porous media. Environ. Sci. Technol. 2000, 34, 3649-3656.

(21) Banitz, T.; Johst, K.; Wick, L. Y.; Fetzer, I.; Harms, H.; Frank, K. The relevance of conditional dispersal for bacterial colony growth and biodegradation. Microb. Ecol. 2012, 63, 339-347, DOI: 10.1007/ s00248-011-9927-3.

(22) Baumgarten, T.; Vazquez, J.; Bastisch, C.; Veron, W.; Feuilloley, M. G. J.; Nietzsche, S.; Wick, L. Y.; Heipieper, H. J. Alkanols and chlorophenols cause different physiological adaptive responses on the level of cell surface properties and membrane vesicle formation in Pseudomonas putida DOT-T1E. Appl. Microbiol. Biotechnol. 2012, 93, 837-845, DOI: 10.1007/s00253-011-3442-9.

(23) Jucker, B. A.; Harms, H.; Zehnder, A. J. B. Adhesion of the positively charged bacterium Stenotrophomonas (Xanthomonas) maltophilia 70401 to glass and Teflon. J. Bacteriol. 1996, 178, 5472-5479. 
(24) Klaine, S. J.; Alvarez, P. J. J.; Batley, G. E.; Fernandes, T. F.; Handy, R. D.; Lyon, D. Y.; Mahendra, S.; McLaughlin, M. J.; Lead, J. R. Nanomaterials in the environment: Behavior, fate, bioavailability, and effects. Environ. Toxicol. Chem. 2008, 27, 1825-1851.

(25) Garcia-Junco, M.; Gomez-Lahoz, C.; Niqui-Arroyo, J. L.; Ortega-Calvo, J. J. Biodegradation- and biosurfactant-enhanced partitioning of polycyclic aromatic hydrocarbons from nonaqueousphase liquids. Environ. Sci. Technol. 2003, 37, 2988-2996.

(26) Tejeda-Agredano, M. C.; Gallego, S.; Niqui-Arroyo, J. L.; Vila, J.; Grifoll, M.; Ortega-Calvo, J. J. Effect of interface fertilization on biodegradation of polycyclic aromatic hydrocarbons present in nonaqueous-phase liquids. Environ. Sci. Technol. 2011, 45, 1074-1081.

(27) Bueno-Montes, M.; Springael, D.; Ortega-Calvo, J. J. Effect of a non-ionic surfactant on biodegradation of slowly desorbing PAHs in contaminated soils. Environ. Sci. Technol. 2011, 45, 3019-3026.

(28) Li, Q. L.; Mahendra, S.; Lyon, D. Y.; Brunet, L.; Liga, M. V.; Li, D.; Alvarez, P. J. J. Antimicrobial nanomaterials for water disinfection and microbial control: Potential applications and implications. Water Res. 2008, 42, 4591-4602.

(29) Brown, L. R. Microbial enhanced oil recovery (MEOR). Curr. Opin. Microbiol. 2010, 13, 316-320. 